\title{
论文
}

\section{鄂西寒武系第二统筑竹寺阶水井沱组放射虫 动物群}

\author{
马强分 ${ }^{1,2}$, 冯庆来 ${ }^{1,2^{*}}$, 曹文超 ${ }^{2}$, 张䂞 $^{2}$, 叶炎 ${ }^{2}$, 顾松竹 ${ }^{2}$ \\ 1. 中国地质大学地质过程与矿产资源国家重点实验室, 武汉 430074; \\ 2. 中国地质大学地球科学学院, 武汉 430074 \\ * 通讯作者, E-mail: qinglaifeng@cug.edu.cn
}

收稿日期：2018-07-17; 收修改稿日期：2019-01-09; 接受日期：2019-01-30; 网络版发表日期：2019-03-21 国家自然科学基金项目(批准号: 41430101)资助

\begin{abstract}
摘要 寒武纪早期放射虫化石稀少, 保存较差, 对其特征和演化缺乏了解. 对鄂西剓归地区寒武系筇竹寺阶水井 沱组进行大量调查, 获得放射虫化石个体 300 多枚, 系统分类属于4种类型, 包括泡沫虫目 2 个新属新种(Paraantygopora porosa和Braunosphaera sinensis) 和 1 个属种分类位置不确定的球形放射虫化石、目科末定分子 1 个(Tetrasphaera? sp.). 其中, 泡沫虫目分子占多数, 约为个体总数量的 $92 \%$, 多数个体 $(73 \%)$ 与奥陶纪早期一些放射虫化石 结构特征类似，壳壁以穿孔板状结构为特征。但格子状球形放射虫在早古生代其他地层中目前尚未有报道。该放 射虫动物群由不同的分类单元的分子组成，化石已经比较常见，壳体结构相当复杂，清晰的同心层状结构已经形 成, 这些特征表明寒武纪第二世筇竹寺期放射虫已经爆发繁盛, 这与浅水相区宏体生物群的爆发繁盛可能为同步 发生.
\end{abstract}

关键词寒武系第二统, 放射虫, 分类学, 演化, 华南, 寒武纪大爆发

\section{1 前言}

放射虫具有无与伦比的精美硅质骨骼，作为现代 海洋中主要的浮游动物类群之一，从海水表层到大洋 深海均有分布. 放射虫自寒武纪出现以来，在地质历 史时期的沉积地层中分布广泛．它演化迅速，生态类 型多样，对于我们了解地史时期的古环境、地层划分 对比及环境与生物之间的协同演化研究均有重要 意义.
目前公认放射虫在寒武纪就已出现，但关于最古 老放射虫化石的时代和特征仍然是未解之谜，广泛存 在争议. Afanasieva等(2005)认为放射虫的鼻祖是四臂 刺形放射虫和球形放射虫，Danelian和Bengtson(2009) 认为最古老的放射虫化石可能为骨针状内射球虫目放 射虫化石, 但这两类刺状化石是否属于放射虫化石, 是 悬而未决的难题(Maletz, 2011).

寒武纪苗岭世与芙蓉世放射虫化石以骨针互相交 错或者相互融合形成的球形壳体为特征，故Dumitrica 
等(2000)据此建立古刺球虫目(Archaeospicularia)，并 认为该目放射虫化石代表了最古老的放射虫动物群. 然而，Braun等(2007)在华南寒武纪纽芬兰统地层中发 现了球形格子状外壳放射虫. 这些放射虫化石层位更 古老，结构类似于较年轻地层中的放射虫化石. 因此, 也有学者认为这些化石数量少、保存差, 存在多解性 (Maletz, 2011). Cao等(2014)在鄂西剓归地区水井沱组 发现了两类球形放射虫化石, Kalimnasphaera $\mathrm{sp}$. 和球 形放射虫化石，其中后者与Braun等(2007)报道的放射 虫化石相同，都有六边形格子状外壳. 此外, Chang等 (2018)在该地区纽芬兰统岩家河组也发现了同样发育 六边形格子状外壳的放射虫化石. 这些发现表明, 寒武 纪早期的确存在壳体结构更先进的放射虫化石.

为了获得更多的放射虫化石材料，查清寒武纪早 期放射虫动物群的组成及其壳体结构特征，2011 2018年间，笔者对峡东地区3个寒武系水井沱组剖面 (九曲脑、罗家村和滚子圤剖面), 进行多次采样, 反复 实验，课题组不同成员多次从各自剖面水井沱组均获 得保存较好的放射虫化石，本文就这些放射虫化石研 究成果予以报道.

\section{2 地质背景及研究剖面概况}

寒武纪早期，扬子板块位于低纬度地区(Cawood
等, 2013; Li等, 2008), 发育从滨海到深海相的地层记 录. 从其西北至东南, 古地理单元可划分为浅海台地相 区，半深海过渡相区和深水盆地相区(冯增昭等, 2001, 2002; 牟传龙等, 2012). 本文研究剖面均位于扬子板块 北部的浅海台地相区, 行政区划属于湖北䄰归地区, 该 地区寒武纪地层发育良好, 出露广泛(图1).

在研究地区, 地层出露受构造作用控制, 新元古代 至古生代地层环黄陵花岗岩体外围呈带状分布, 沉积 记录连续，出露完整，古生物化石丰富(图1b; 钱逸等, 1979; 林天瑞等，2004; 刘鹏举等，2012; 杨爱华等, 2015). 其寒武系自下而上划分为岩家河组、水井沱 组、石牌组、天河板组、石龙洞组等(张文堂等, 1957; 陈平, 1984; 朱茂炎, 2010).

研究剖面共三条，均位于湖北省宜昌市行政区境 内. 其一, 罗家村剖面(LJC, 30 47'41"N , 110 $54^{\prime} 50^{\prime \prime} \mathrm{E}$ ), 为人工采石场(图 $2 \mathrm{a}$ 和 $\mathrm{b}$ ), 位于䄰归县城以西约 $10 \mathrm{~km}$ 的 罗家村南侧. 该剖面底部(第1层)为岩家河组, 主体为 水井沱组(第2 5层，厚 $57 \mathrm{~m}$ ), 顶部(第6层)为石牌组(图 3). 第2层以黑色碳质泥岩为主, 夹薄层灰岩, 上部含灰 岩结核, 泥岩中产三叶虫Tsunyidiscus; 第3层为黑色泥 灰岩, 偶含灰岩结核; 第4层为黑色碳质页岩, 产三叶虫 Tsunyidiscus 和Zhenbaspis; 第5层为钙质泥岩. 第1层岩 家河组含丰富的小壳化石, 地质时代为寒武纪纽芬兰 世(Chang等，2018)。第2层上部至第5层产三叶虫Tsu-
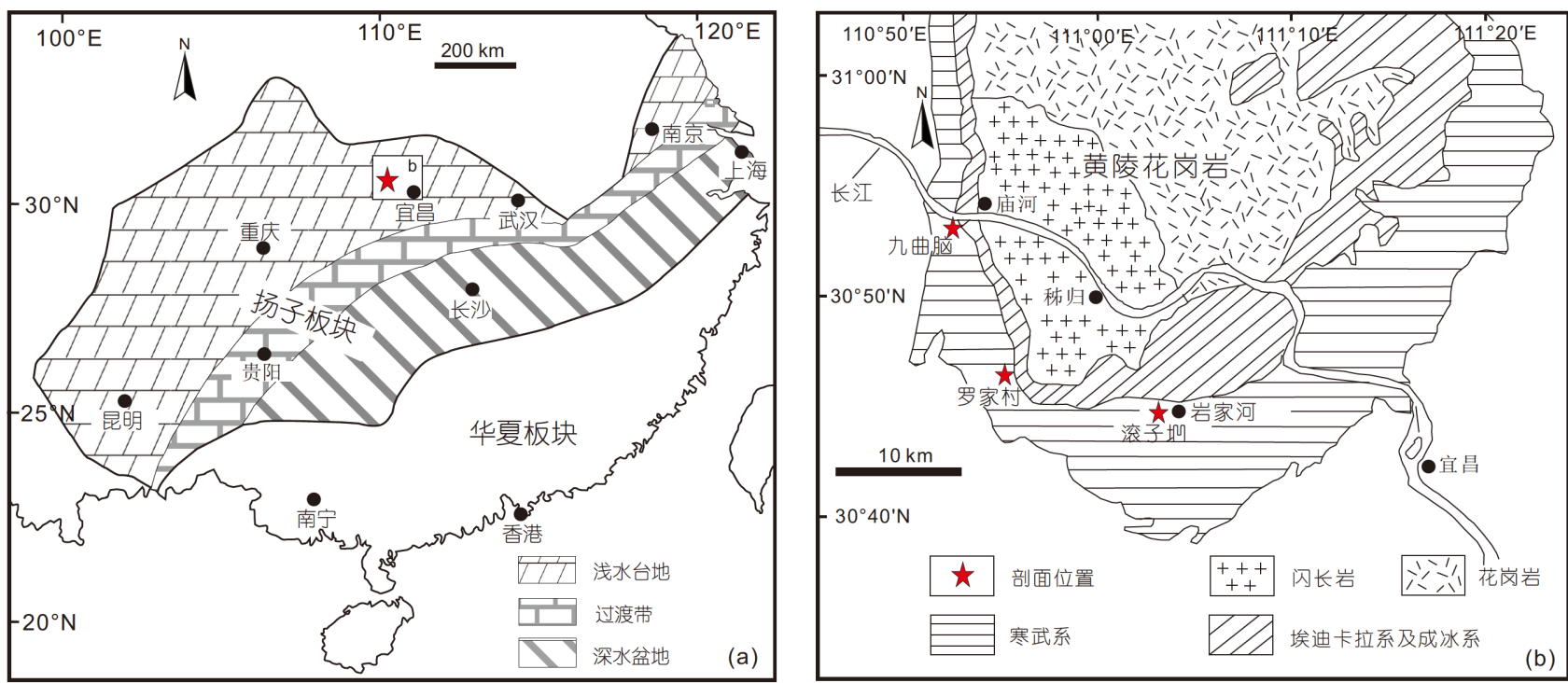

图 1 扬子区寒武纪第二世筑竹寺期岩相古地理图(a)和湖北三峡地区地质简图及水井沱组研究剖面位置(b) 据冯增昭等(2001, 2002)、牟传龙等(2012)略有修改 

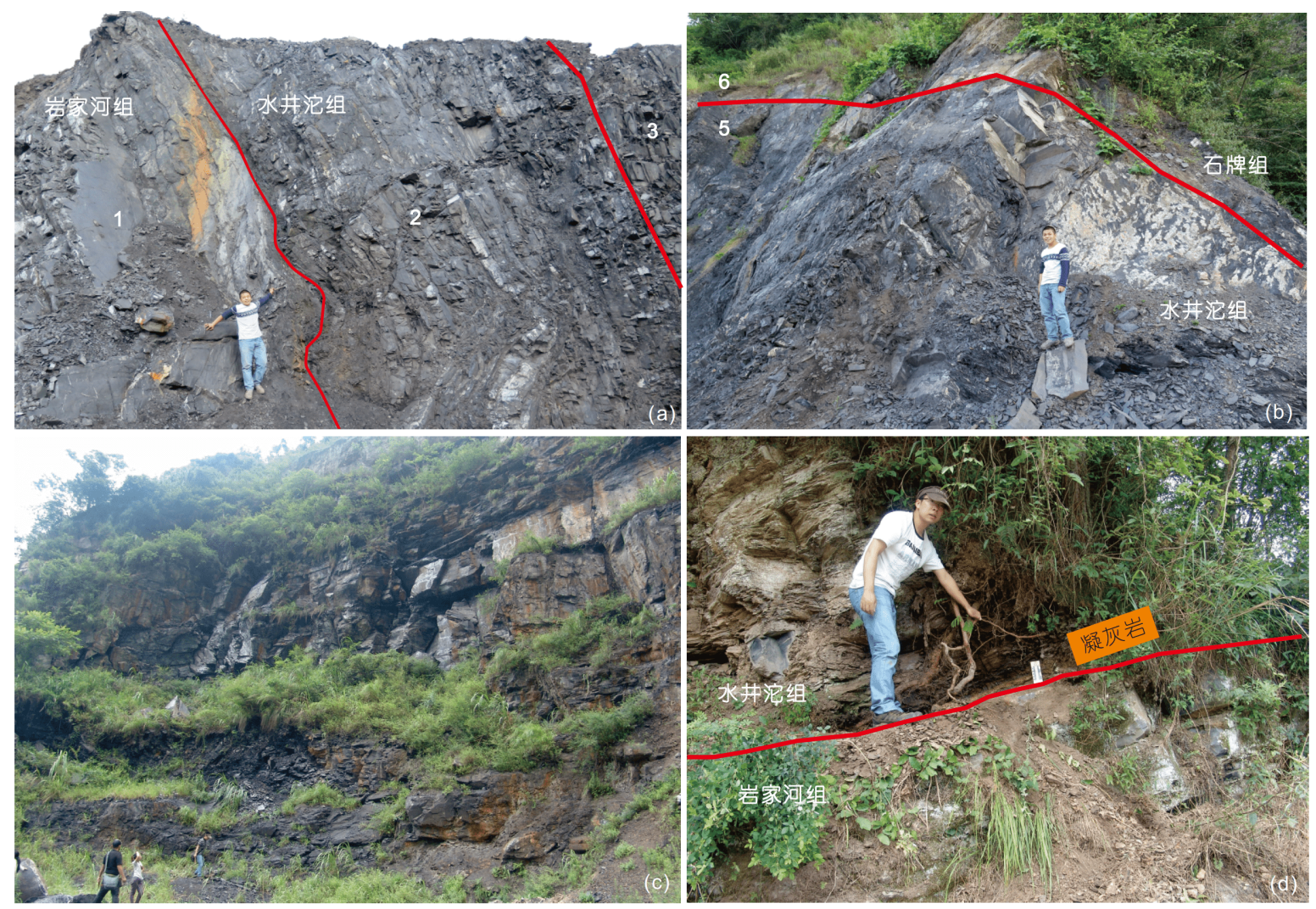

图 2 研究剖面野外照片

(a) 罗家村剖面岩家河组和水井沱组; (b) 罗家村石牌组与水井沱组界限; (c) 九曲脑剖面水井沱组; (d) 滚子圤剖面岩家河组与水井沱组组界限

nyidiscus 和Zhenbaspis(图3 4), 所以水井沱组可以划归 寒武系第二统.

另一条剖面为九曲脑剖面(JQN, $30^{\circ} 53^{\prime} 08^{\prime \prime} \mathrm{N}, 110^{\circ}$ $52^{\prime} 01^{\prime \prime} \mathrm{E}$; 图2c), 位于剓归西部九曲脑村旁, 长江南岸, 剓归至九畹溪公路横墩岩隧道西出口附近. 该剖面底 部岩家河组产丰富的小壳化石, 地质时代为寒武纪纽 芬兰世(朱茂炎等, 2019); 水井沱组与岩家河组呈平行 不整合接触, 厚 $59 \mathrm{~m}$, 产出大量寒武纪筇竹寺期三叶虫 化石，包括Sinodiscus、Tsunyidiscus及Hupeidiscus 等; 石牌组与水井沱组呈整合接触(图3, CaO等, 2014). 该 剖面水井沱组分为 3 个岩性段: 下段(第2层)为薄层状 黑色页岩段，夹大量灰岩结核，结核中产出球形放射 虫Kalimnasphaera sp.(Cao等, 2014); 中段(第3 8层)岩 性主要为黑色灰岩与碳质泥岩; 上段(第9层)为生物碎 屑灰岩段.

第三条剖面为滚子地剖面 $\left(\mathrm{GZA}, 30^{\circ} 44^{\prime} 55^{\prime \prime} \mathrm{N}, 111^{\circ}\right.$ $03^{\prime} 58^{\prime \prime} \mathrm{E}$; 图2d), 位于剓归南部岩家河行政村滚子地自
然村旁. 该剖面下部为岩家河组, 上部为水井沱组(厚 $68 \mathrm{~m})$, 顶部为石牌组. 岩家河组研究较好, 产丰富的小 壳化石, 自下而上可划分为Anabarites trisulcatus-Protohertzina anabarica组合带, Purella antiqua组合带, 以 及Aldanella yanjiaheensis组合带(陈平, 1984; 郭俊锋, 2009; Peng, 2009; Guo等, 2014; 潘时妹等, 2018), 可与 滇东地区小壳化石带很好对比(Steiner等, 2007), 其地 质年代相当于纽芬兰统肖滩阶(Guo等，2014; Peng, 2009; Steiner等, 2007). 水井沱组分为3个岩性段, 第一 段为黑色泥岩段, 含大量灰岩结核, 其中部产三叶虫 Tsunyidiscus(图4h); 第二段为泥灰岩段, 产三叶虫Tsunyidiscus, 腕足Eohadrotreta、Palaeobolus、Spinobolus、Lingulellotreta、Eoobolus(Zhang等，2016); 第三 段为生物碎屑灰岩段(汪洋等, 2010)(图3). 水井沱组下 段底部(三叶虫Tsunyidiscus 首现点之下)发育1层薄的 凝灰岩，其中的锆石年龄为 $(526 \pm 5.4) \mathrm{Ma}(\mathrm{Okada}$ 等, 2014; Zhang等，2016)显示水井沱组最下部不早于纽 


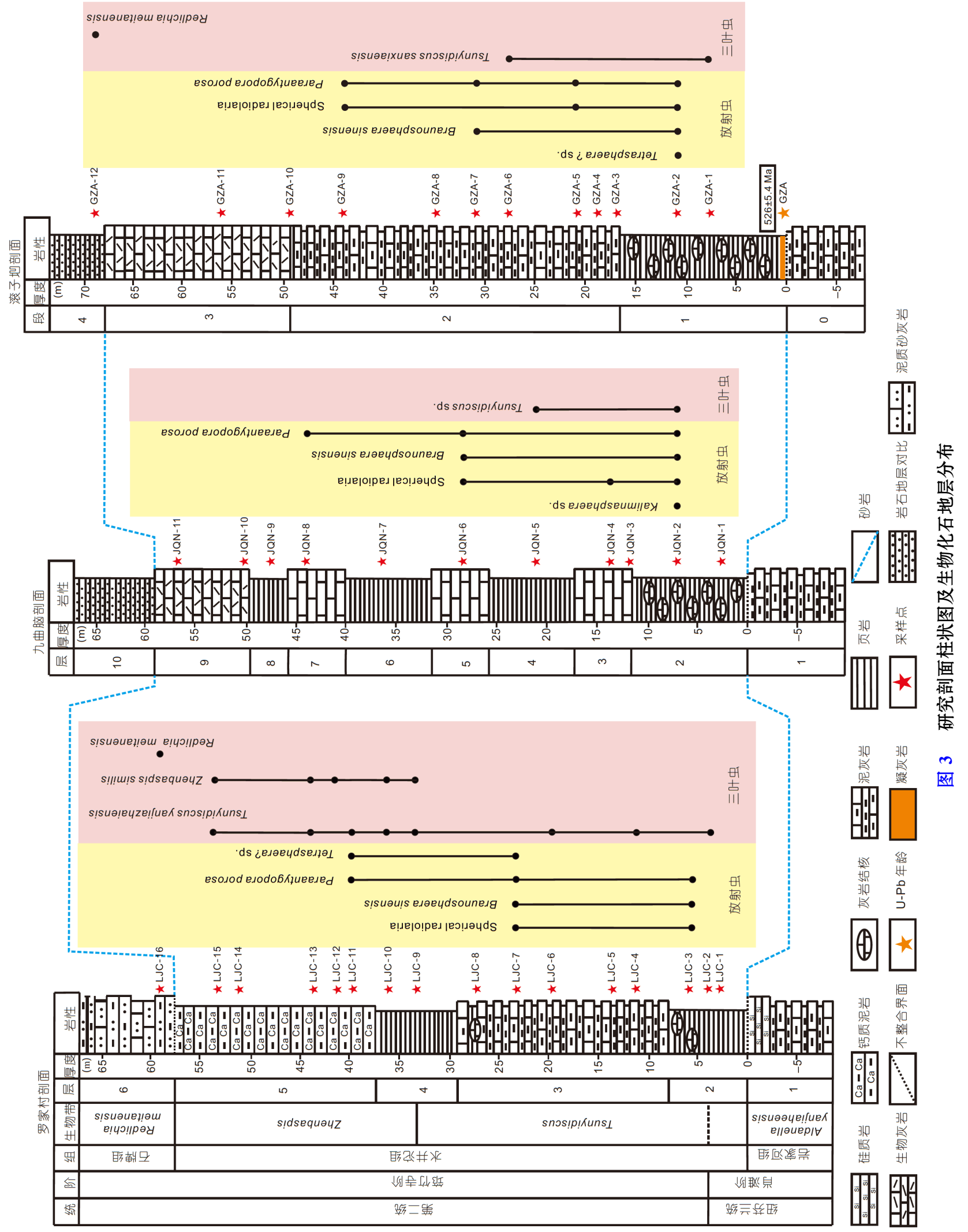



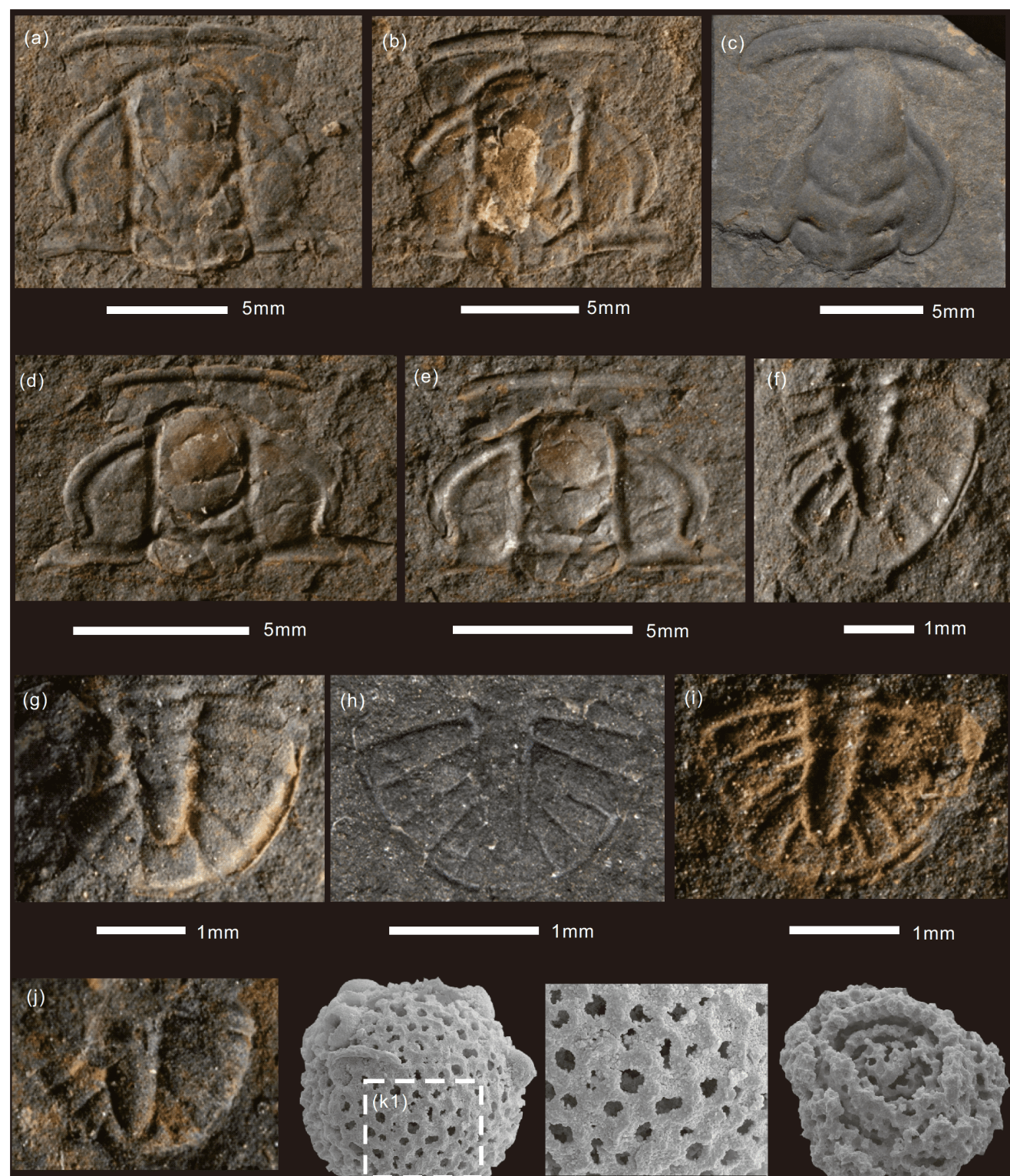

$5 \mathrm{~mm}$
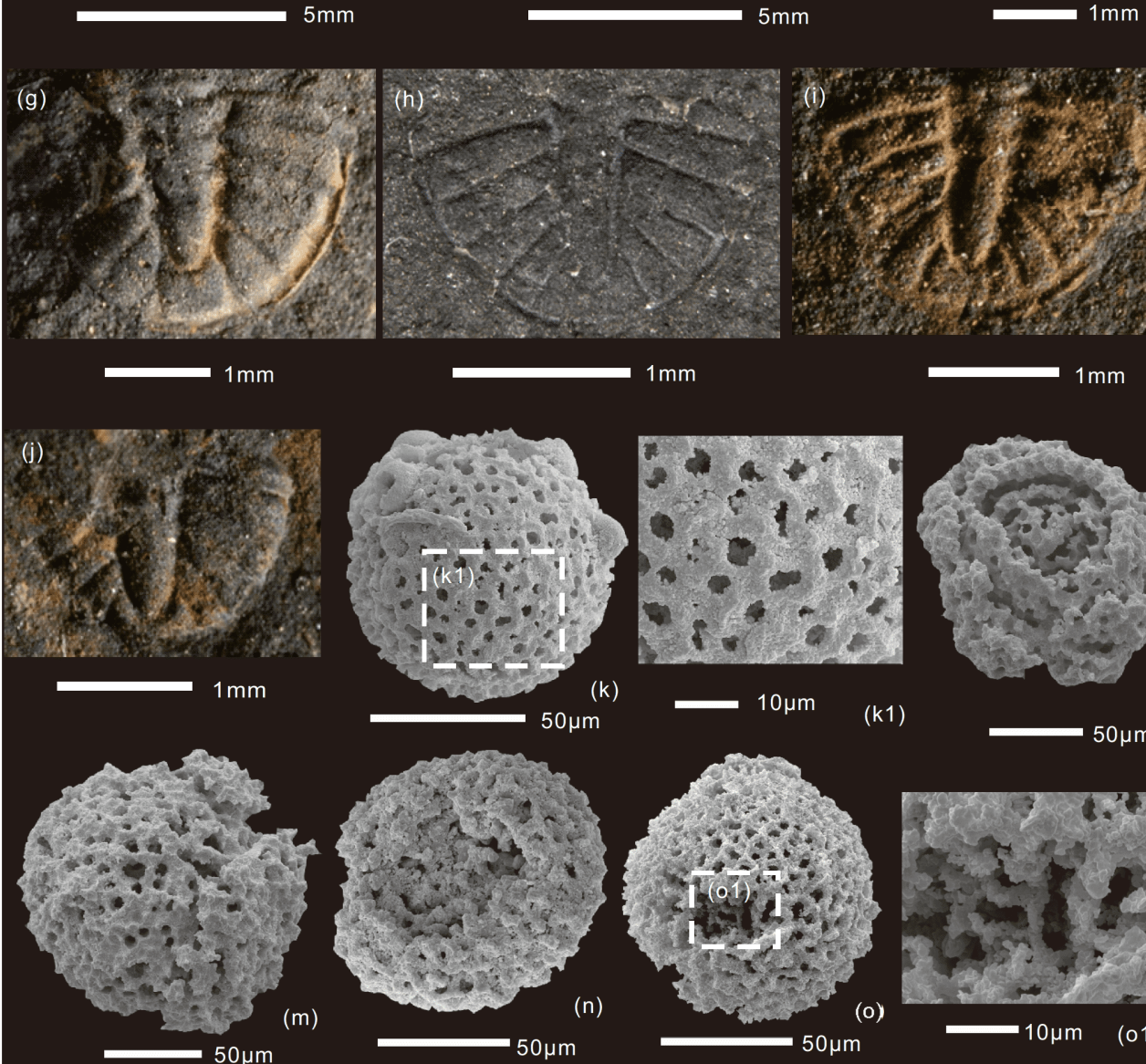

(k1)

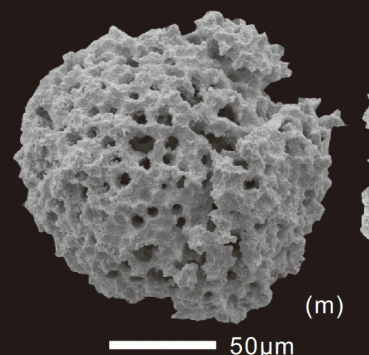

图 4 湖北剓归地区研究剖面三叶虫化石及放射虫化石

三叶虫: (a) (b), (d) (e), Zhenbaspis similis: (a) LJC-9; (b) LJC-9; (d) LJC-9; (e) LJC-9. (c) Redlichia meitanensis, GZA-12. (f) (j), Tsunyidiscus yanjiazhaiensis, (f) LJC-9; (g) LJC-9; (h) GZA-1; (i) LJC-10; (j) JQN-5. 放射虫Tetrasphaera? sp.: (k) LJC-7; (k1) LJC-7(标本(k)局部放大, 展示壳 壁结构和壳孔形态); (1) LJC-7; (m) LJC-7; (n) LJC-11; (o) LJC-7; (o1) LJC-7(标本(o)局部放大) 
芬兰统肖滩阶顶部, 其主体部分为寒武系第二统(朱茂 炎等, 2019).

研究区水井沱组与上覆地层石牌组呈整合接触, 石牌组主要岩性为粉砂岩和砂质泥岩, 含薄层状泥灰 岩, 产三叶虫化石Redlichia meitanensis(图4c), 地质时 代相当于寒武纪第二世筑竹寺晚期(朱茂炎等, 2019; Zhang等, 2016).

\section{3 研究材料及方法}

自2011年7月以来, 笔者多次赴湖北剓归地区进行 野外工作, 详细测量了柇归九曲脑、罗家村和滚子地 剖面, 对水井沱组的灰岩结核、泥灰岩和薄层微晶灰 岩进行放射虫样品采集, 每个样品至少 $5 \mathrm{~kg}$; 同时, 逐 层收集各类化石, 用于地质时代研究. 样品在“中国地 质大学地质过程与矿产资源国家重点实验室”微体古 生物实验室进行放射虫处理工作.

首先将样品碎成直径 $1 \mathrm{~cm}$ 大小, 在室内将所取样 品置于浓度为 $5 \%$ 的冰醋酸溶液中浸泡, 在室温条件下 每24h冲洗、换酸一次. 所得的酸性残渣用水中和至中 性. 如此重复约半个月, 获得足够的残渣. 将溶出的残 渣用 300 目 $(0.054 \mathrm{~mm})$ 笛子洗净, 再转置于烧杯中自然 晾干. 然后将处理好的样品均匀地铺在玻璃板上, 在 体式显微镜下挑出保存好的放射虫标本. 随后将精选 标本粘到小铜台上, 用扫描电子显微镜(SEM)照相以 作进一步的研究.

\section{4 水井沱组放射虫动物群组成和壳体结构 特征}

大量调查表明, 研究剖面钻质泥岩和灰岩结核中 发育丰富的球形多囊虫类(spherical polycystine)放射 虫化石．在罗家村剖面水井沱组地层中，获得放射虫 化石141枚; 九曲脑剖面获得133枚，滚子圤剖面获得 95枚. 该放射虫动物群以球形泡沫虫目为主，经鉴定 建立新属新种 2 个(Paraantygopora porosa gen.et sp. nov.和Braunosphaera sinensis gen.et sp. nov.), 未定种 1 个(Tetrasphaera? sp.), 还有 1 个属种分类位置不确定 的球形放射虫化石. 所以, 该放射虫动物群目前包括了 4种分类形态, 分异度较高(图4 6).

水井沱组除了放射虫化石外，相同层位还发现有
三叶虫、小壳化石、高肌虫、等刺虫等后生动物化 石. 经鉴定共生的三叶虫以古盘虫类Tsunyidiscus yanjiazhaiensis Zhang et al. in Yin and Li 为主(Dai等, 2016) (图4). 所以, 该放射虫动物群地质时代为寒武纪第二 世筑竹寺期.

从壳壁结构来看，当前放射虫动物群以“穿孔板” 状壁为主，包括属种未定的球形放射虫，约占壳体总 数的 $73 \%$. 这类壳壁为绷带状板片融合形成网状壳, 不 同种类绷带状板片宽窄不同. 壳壁发育小的、密集的 孔, 孔的周缘为向外翻的孔缘, 孔缘将相邻壳壁连接 起来(图7). 这些特征与奥陶纪早期的一些属种类似, 例如Antygopora ordovicica Maletz and Bruton和 Beothuka stoogei Won and Iams等.

另外约 $27 \%$ 的壳体具有网状壳壁结构. 其中, Braunosphaera sinensis的壳壁由较厚的骨棒融合形成, 具有规则的六边形结构(图6h1、6i1、6j1、6k1), 与其 他早古生代放射虫化石结构明显不同, 而更类似于晚 古生代和中生代一些球形格子状壳壁结构. 这也是有 学者对前人报道的寒武系下部这类放射虫化石存疑的 主要原因，但不同研究人员、从不同剖面、不同岩性 中均获得这类放射虫化石, 说明这类化石的确为寒武 纪早期的放射虫化石. 所以，继续深入研究这类化石， 特别是其内部结构和地层分布，对探索放射虫早期演 化非常必要.

Tetrasphaera? sp.的壳壁也是由较厚的骨棒融合 形成, 但壳孔大小和形态均不规则. 这类化石结构上 与Tetrasphaera Wang类似，但在后者原文中该属的壳 壁是不清楚的. 所以，当前的Tetrasphaera? sp. 能否与 Tetrasphaera Wang对比是存疑的.

从壳体结构来看, 当前放射虫动物群全部发育了 同心壳结构, 有的同心壳发育完整, 如Braunosphaera sinensis、Tetrasphaera? sp.和Paraantygopora porosa; 有的结构不完整, 壳壁间距很小, 如属种未定的球形 放射虫. 有的壳壁较多、较薄; 有的壳壁较少、较厚. 该放射虫动物群壳体结构的共同特点是壳壁之间的连 接棒或骨片均较薄弱、纤细.

从内部结构来看, 多数壳体髓壳内部是空的, 没有 发育初始骨针, 应当归属泡沫虫目, 包括Paraantygopora porosa、Braunosphaera sinensis和属种未定的球 形放射虫化石. Tetrasphaera? sp. 的髓壳内部结构不 清楚. 


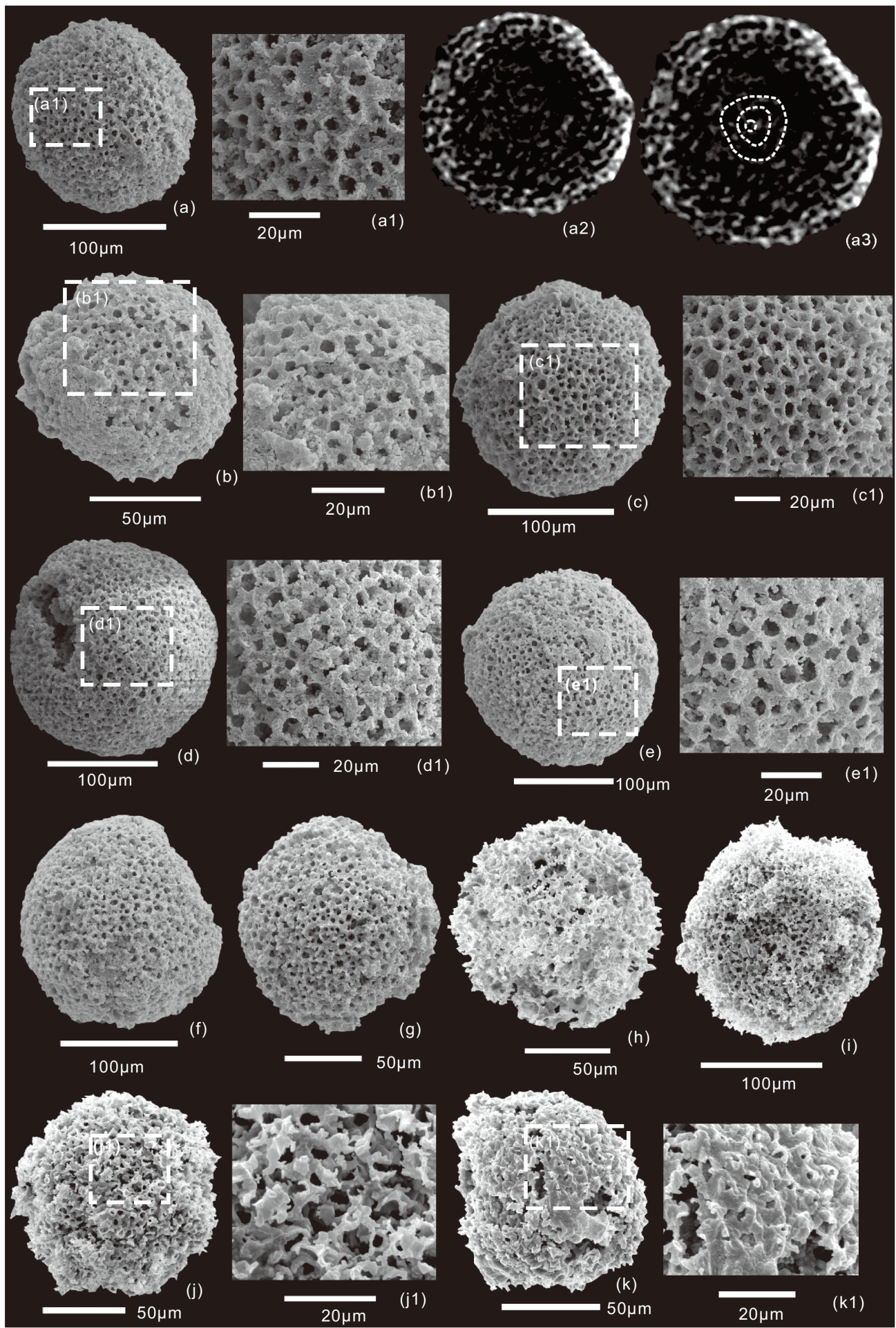

图 5 䄰归地区下寒武统水井沱组剖面放射虫化石

(a2)和(a3)为Micro-CT照片, 其余为扫描电子显微镜照片. (a) (i) Paraantygopora porosa gen. et sp. nov.: (a) LJC-3(正模); (a1) LJC-3, 标本(a)局 部放大, 展示壳壁结构, (a2) (a3) 显示模式标本多层同心壳结构; (b) LJC-7; (b1) LJC-7, 标本(b)局部放大; (c) LJC-7; (c1) LJC-7, 标本(c)局部放 大; (d) LJC-7; (d1) LJC-7, 标本(d)局部放大; (e) LJC-3; (e1) LJC-3, 标本(e)局部放大; (f) LJC-7; (g) LJC-7; (h) JQN-2; (i) JQN-2. (j) ( (k) 球形放射 虫Spherical radiolaria: (j) JQN-2; (j1), JQN-2, 标本(j)局部放大; (k) JQN-2; (k1) JQN-2, 标本(k)局部放大 


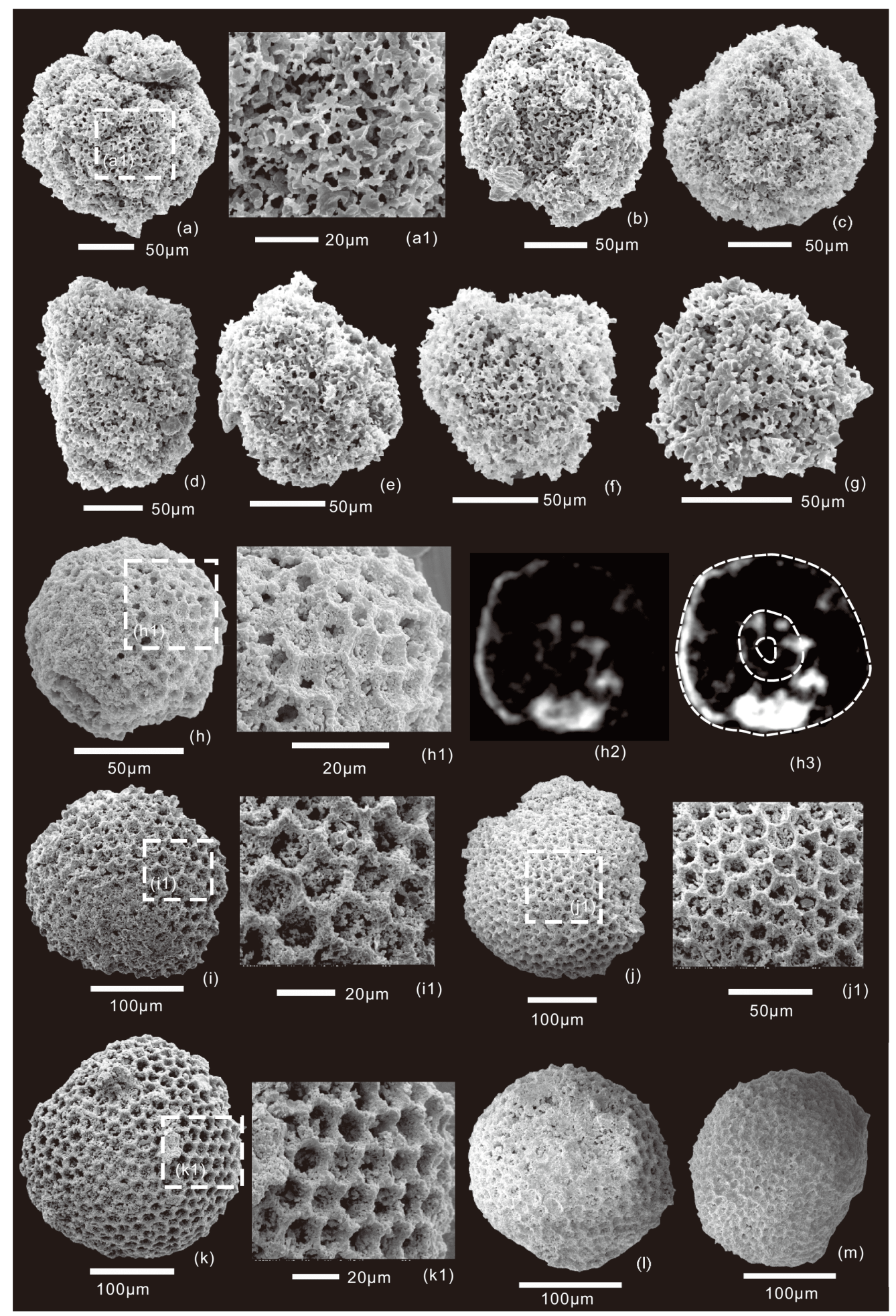

图 6 䄰归地区下寒武统水井沱组剖面球形放射虫化石

(h2)和(h3)为Micro-CT照片, 其余为扫描电子显微镜照片. (a) (g) Spherical radiolarian: (a) JQN-2; (a1) JQN-2, 标本(a)局部放大; (b) JQN-4; (c) JQN-4; (d) JQN-2; (e) JQN-2; (f) JQN-2; (g) JQN-6. (h) (m) Braunosphaera sinensis gen.et sp. nov. : (h) LJC-7(正模); (h1) LJC-7, 标本(h)局部放 大; (i) JQN-2; (i1) JQN-2, 标本(i)局部放大; (j) JQN-2; (j1) JQN-2, 标本(j)局部放大; (k) JQN-2; (k1) JQN-2, 标本(k)局部放大; (l) GZA-2; (m) GZA-2 


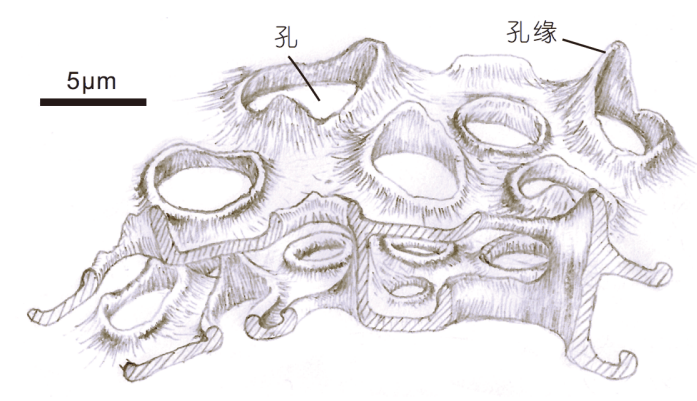

图 7 放射虫化石Paraantygopora porosa壳壁结构素描

无论是从壳体圈层结构、髓壳内部结构, 还是壳 壁结构来看, 该放射虫动物群都是发育非常完好, 多 数放射虫化石可以与奥陶纪早期一些放射虫化石较好 地对比.

\section{5 讨论}

放射虫作为一种海生浮游单细胞生物(Campbell, 1954), 其起源和演化问题一直深受古生物学家关注. 尽管分子生物学研究表明, 放射虫在新元古代就已出 现(例如, Simpson等, 2002; Danelian和Moreira, 2004; Ishitani等, 2011; Decelle等, 2012), 然而迄今为止仍然 没有可靠的前寒武纪放射虫化石的证据，寒武纪早期 的化石证据也知之甚少. 目前发现于前寒武纪时期的 放射虫化石(Cayeux, 1894; David和Howchin, 1896; 黄 慧琼等, 1988), 由于缺乏可靠的年代地层证据和标本 鉴定等问题, 均被否认(Deflandre, 1949; Nazarov, 1973, 1988; De Wever等, 2001; Aitchison等, 2017).

Afanasieva等(2005)系统总结了放射虫的化石资 料, 认为放射虫的鼻祖是四臂刺形放射虫和球形放射 虫, 在寒武纪这两类放射虫快速演化、并辐射形成放 射虫已知主要类群，包括泡沫虫目(Spumellaria)、内 射球虫目(Entactinaria)、古刺球虫目 (Archaeospicularia)、隐管虫目(Latentifistularia，也有称为十字多囊虫 目Stauraxonaria)和罩笼虫目(Nassellaria), 只有阿尔拜 虫目(Albaillellaria)出现较晚. 由于分类学认识的分歧, 该观点没有得到放射虫研究者认同，许多方面还缺乏 放射虫化石资料支撑. Danelian和Bengtson(2009)在澳 大利亚南部斯科特山系阿贾克斯灰岩组中发现了一个 可能的骨针状内射虫目放射虫化石, 认为与早古生代 Palaeoscenidiidae有关，该记录可能代表已知最古老
的、可能的放射虫化石. 但是也有人认为该化石还不 能确定为放射虫化石, 也可能为形态比较特殊的海绵 骨针化石(Maletz, 2011).

寒武纪保存较好的放射虫化石最早发现于湖南地 区芙蓉统(Furongian)碧条组生物碎屑灰岩中(Dong等, 1997), 随后在澳大利亚昆士兰地区苗岭统(Miaolingian)(Won和Below，1999), 俄罗斯戈尔诺阿尔泰斯克 地区第二统(Cambrian Series 2)(Obut和Iwata, 2000)以 及加拿大纽芬兰地区芙蓉(Furongian)(Won和Iams, 2002)地层中, 也发现了保存精美的放射虫动物群(图 8). 这类放射虫化石由一些自由独立、互相交错或者 相互融合形成格子壳的骨针构成球状壳体, 被归入古 刺球虫目(Dumitrica等, 2000). 不少学者认为, Archaeospicularia被认为是最古老的放射虫动物群, 推测该放 射虫目随后通过减少初始骨针的数目等演化形式形成 了内射虫目、阿尔拜目和泡沫虫目 (Dumitrica等, 2000; Maletz, 2011).

近10多年来, 在华南寒武系底部地层中报道了一 些具格子状壳的球形放射虫(Braun等, 2007; Cao等, 2014; Chang等, 2018)(图8). 该类格子状外壳球形放射 虫是已知最古老的放射虫, 显然不属于古刺球虫目. 由 于放射虫标本数量和保存等问题, 导致许多研究人员 质疑这类放射虫报告的准确性. 笔者多次、多条剖面 的调查结果表明, 不仅格子状球形放射虫, 而且穿孔 板状球形放射虫, 确实普遍存在于寒武系第二统地层 中. 该结果表明, 古刺球虫目可能代表了放射虫的演 化谱系之一, 寒武纪早期还存在其他放射虫演化谱系, 放射虫的起源和演化应该能够向前追溯到寒武纪最早 期, 甚至埃迪卡拉纪末期.

本文报道了放射虫化石4种类型, 综合前人报道成 果, 华南寒武纪早期共发现放射虫化石6种类型, 包括 Kalimnasphaera、Tetrasphaera?、Paraantygopora porosa、spherical radiolarian(本文)、Blastulospongia、 Braunosphaera sinensis(Conway和Chen, 1990; Braun 等, 2007; Cao等, 2014; Chang等, 2018; 本文), 其中前4 种类型放射虫化石在壳体结构特征方面可以与奥陶纪 放射虫化石对比. 奥陶纪放射虫化石与寒武纪早期放 射虫动物群相比较, 壳壁数目更少、壳孔更少更大、 放射刺更发育. 由于寒武纪中晚期放射虫化石与早期 非常不同，寒武纪早期与奥陶纪放射虫之间的演化关 系和过程还不清楚, 尚待深入研究. 


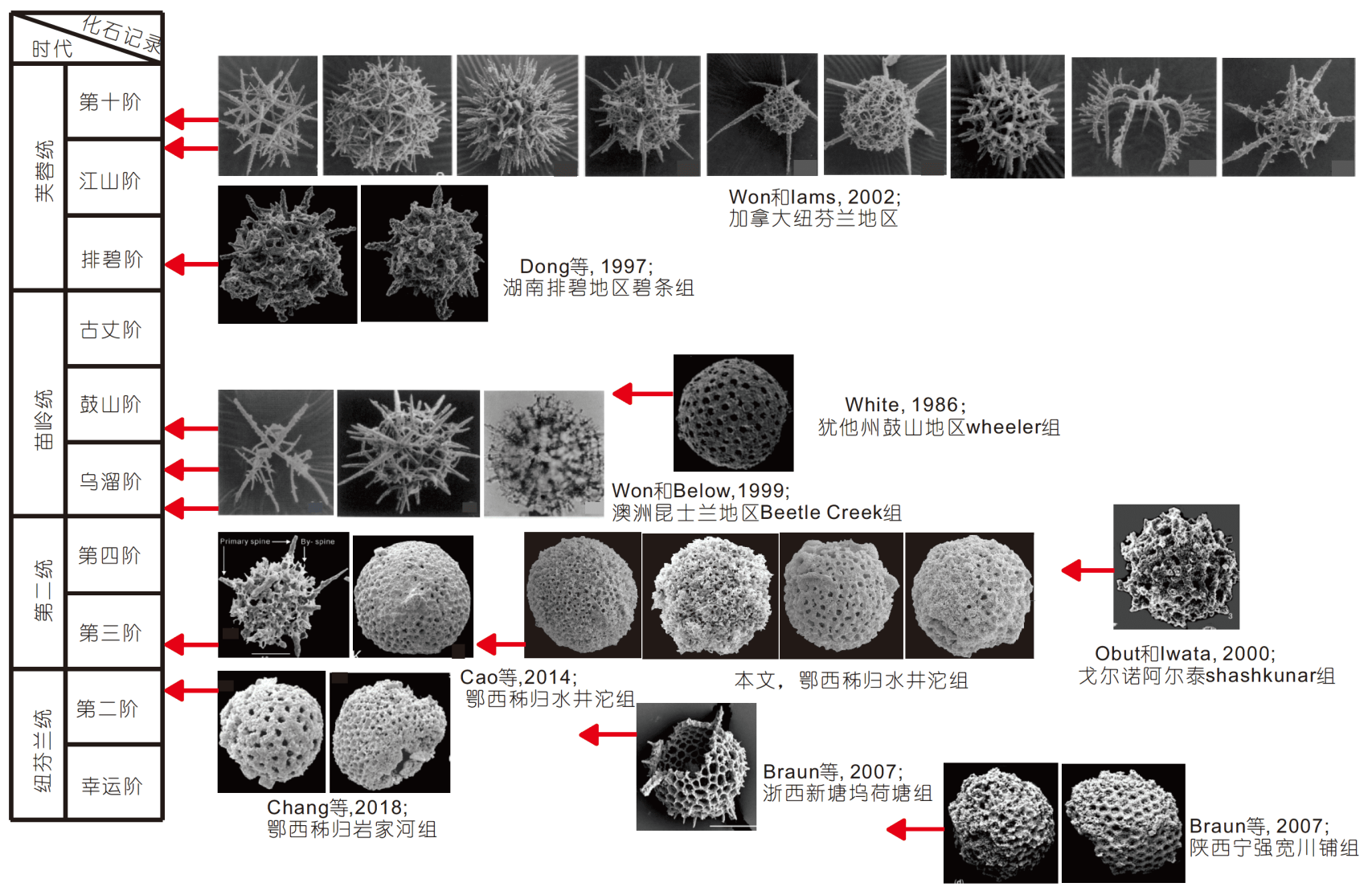

图 8 寒武纪放射虫化石地层分布

从高级分类单元来看, 寒武纪早期放射虫化石多 数属于泡沫虫目，寒武纪中晚期常见的古刺球虫目尚 未在寒武纪早期地层中发现代表分子. 另一方面，寒 武纪第二统放射虫壳体化石已经比较常见，其结构相 当复杂. 这些特征表明，寒武纪第二世筇竹寺期放射 虫已经爆发繁盛，这与浅水相区宏体生物群的爆发繁 盛可能为同步发生(Shu等, 2014; 张兴亮和舒德干, 2014).

\section{6 放射虫化石描述}

所有标本均采自湖北䄰归地区水井沱组，保存于 中国地质大学(武汉)地质过程与矿产资源国家重点实 验室. 所有放射虫化石标本SEM照相和能谱分析在中 国地质大学(武汉)地质过程与矿产资源国家重点实验 室完成，Micro-CT照片在中国地质大学(武汉)生物地 质与环境地质国家重点实验室拍摄. 放射虫的分类学
研究依据De Wever等(2001)分类系统.

放射虫亚纲RADIOLARIA Müller, 1858

多囊虫超目POLYCYSTIDA Ehrenberg, 1838, emend. Riedel, 1967

目和科末定Order and Family incertae

四球虫属Genus Tetrasphaera Wang, 2008

模式种Tetrasphaera kuruktagensis Wang,

2008

四球虫?(未定种)Tetrasphaera? sp.

图 $4 \mathrm{k} \sim 4 \mathrm{o}$

鉴定材料：罗家村剖面的第3层泥灰岩产出7枚化 石, 第5 层钻质泥岩产出 13 枚化石; 滚子圤剖面灰岩结 核中产出8枚化石. 扫描电子显微镜能谱分析表明，壳 体成分为 $\mathrm{SiO}_{2}$, 表明由石英组成, 属于硅质壳体(图9a).

描述：壳体球形，直径为 $87.5 \sim 142 \mu \mathrm{m}$ (平均值 


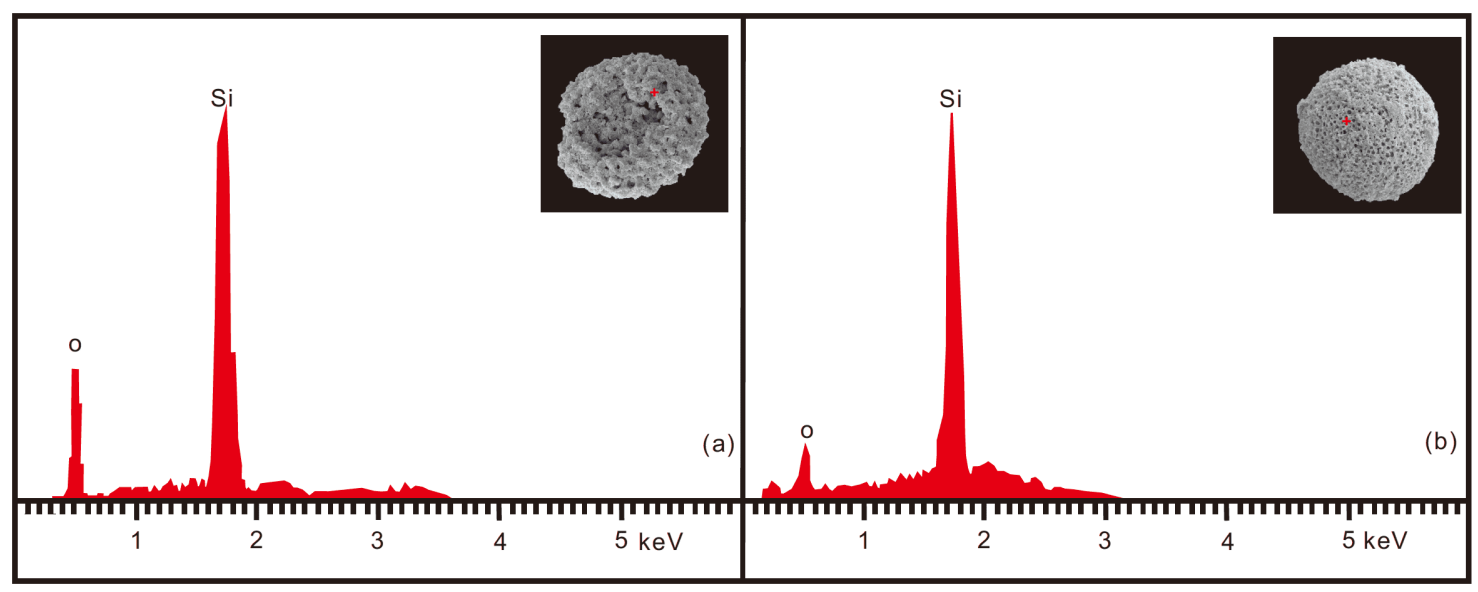

图 9 放射虫壳体成分分析

(a) Tetrasphaera? sp.(图4n); (b) Paraantygopora porosa(图5e)

$108 \mu \mathrm{m}$ ), 由 4 个同心格子壳组成, 1 个外壳和 3 个髓壳(图 $41)$. 外壳和各髓壳表面都发育大量圆形小孔，壳孔直 径为2.2 $6.9 \mu \mathrm{m}$ (平均值 $4.2 \mu \mathrm{m}$ ), 相邻壳孔平均间距为 $5 \mu \mathrm{m}$. 壳壁厚度和相邻壳之间的距离大致相等, 约为 $8.7 \mu \mathrm{m}$. 最里面的髓壳比较大, 直径约为外壳的 $1 / 3$. 不 发育外刺和辅刺.

比较：当前标本具有4个等间距的同心圆格子壳, 与王玉净等(2008)在新疆塔里木盆地中奥陶统大坪阶 地层中发现的Tetrasphaera kuruktagensis相似. 当前标 本与后者的区别在于内部髓壳较大，壳体间无明显的 放射樑. 由于四球虫属模式标本保存较差，描述简单， 当前标本能否与其对比, 尚不清楚, 故暂将其归入四球 虫属(Tetrasphaera Wang).

产地和层位: 罗家村剖面第3层和第5层, 滚子地剖 面第1段(图3).

泡沫虫目SPUMELLARINA Ehrenberg, 1875

翻孔球科 ANTYGOPORIDAE Maletz \& Bruton, 2007

拟翻孔球属(新属)Genus Paraantygopora n. gen. Ma \& Feng

模式种 Paraantygopora porosa n. sp.

属名来源：因新属壳体形状与Antygopora Maletz \& Bruton, 2005相似而命名. Para(相似的)+Antygopora (已有属名).
鉴定要点: 新属壳体球形或次球形, 无外刺, 由多 层同心壳组成; 壳薄, 为穿孔板状壳; 孔小, 密集, 近圆 形, 具向外隆起的孔缘, 孔缘高低不等, 较高部分与外 壳相连; 壳间距相等且窄. 中心囊无初始骨针.

比较: 新属壳体由穿孔板状同心壳组成, 壳壁发育 密集的小孔, 孔的周缘具有向外隆起的圆形孔缘, 该特 征与Antygopora Maletz \& Bruton, 2005和Beothuka Aitchison, Flood \& Malpas, 1998类似. 但Antygopora 同心壳层数目较少, 且壳之间的间距不等, 可以区别目 前新属; Beothuka发育双极性刺, 与当前新属不同.

产地和层位: 罗家村剖面第2层、第3层和第5层, 九曲脑剖面第2层、第5层和第7层, 滚子地剖面第1段 和第2段(图3); 寒武纪纽芬兰世和第二世, 华南.

多孔拟翻孔球虫(新种)Paraantygopora porosa $\mathrm{n}$. sp. Ma \& Feng

\section{图5a $\sim 5 \mathrm{i}$}

鉴定材料: 罗家村剖面第2层灰岩结核中产出12枚 化石, 第3层泥灰岩中产出21枚化石, 第5层铻质泥岩产 出34枚化石; 九曲脑剖面第2层灰岩结核中产出38枚化 石，第5、7层灰岩中产出44枚化石; 滚子牭剖面第1段 灰岩结核中产出10枚化石, 第2段泥灰岩中产出 20 枚化 石. 扫描电子显微镜能谱分析表明，壳体成分为 $\mathrm{SiO}_{2}$, 表明由石英组成, 属于硅质壳体(图9b).

种名来源: poros-a-um(Latin, adj.)=porous(孔状的) 
描述: 壳体呈球形或次球形, 外壳直径93 185 $\mu \mathrm{m}$ 不等(平均值 $142 \mu \mathrm{m}$, 正模为 $147 \mu \mathrm{m}$ ). 由 $8 \sim 10$ 个间距相 等的同心壳组成，壳间距为 $5 \sim 10 \mu \mathrm{m}$ (平均值约为 $8 \mu \mathrm{m}$, 正模为 $9 \mu \mathrm{m})$. 各层壳表面具小而致密的孔，孔口呈圆 形、次圆形, 壳孔直径约为 $3 \sim 5 \mu \mathrm{m}$ (平均值 $4 \mu \mathrm{m}$, 正模 $5 \mu \mathrm{m})$. 孔缘向外隆起, 高低不等, 较高部分与外壳相 连. 相邻壳孔之间为绷带状板片, 其宽度约为 $5 \mu \mathrm{m}$ (图 $5 \mathrm{~b} 1 、 5 \mathrm{~d} 1 、 5 \mathrm{~h})$. Micro-CT照相揭示内核近球形，无初 始骨针(图5a2、5a3).

比较：新种的外形与Maletz和Bruton(2005)在早奥 陶世晚期Arenigian阶Didymograptellus bifidus笔石带 地层中发现的泡沫虫Antygopora ordovicica十分相似, 区别在于新种的壳体有多个同心球壳，壳间距相等, 而Antygopora ordovicica的壳体只有 3 个球壳，且壳间 距不相等, 自内向外间距逐渐增大. Beothuka stoogei Won and Iams, 2011发育6个圆柱形外刺, 可以与当前 新种区分.

正模：图5a，样品编号LJC-3；SEM照片编号4-2018.

产地和层位：罗家村剖面第2层、第3层和第5层, 九曲脑剖面第2层、第5层和第7层, 滚子地剖面第 1 段 和第2段(图3).

属和种未定Genus and Species incertae 球形放射虫Spherical radiolaria

图 $5 \mathrm{j} \sim 5 \mathrm{k}$, 图 $6 \mathrm{a} \sim 6 \mathrm{~g}$

鉴定材料: 罗家村剖面第2层灰岩结核中产出6枚 化石，第3层泥灰岩中产出8枚化石; 九曲脑剖面第2层 灰岩结核中产出 12 枚化石，第3、5层灰岩中产出 18 枚 化石; 滚子吅剖面第1段灰岩结核中产出7枚化石, 第2 段泥灰岩中产出 15 枚化石.

描述: 壳体近球形, 无外刺, 直径96 174 $\mu \mathrm{m}$ (平均 值 $134 \mu \mathrm{m})$. 壳体由多层壳组成, 每层壳很薄, 发育不完 整，为绷带状板片组成的网状壳，或称为穿孔板状壳; 朋带状板片窄; 壳孔小, 密集, 形状不规则, 呈圆形、次 圆形或拉长形, 孔的周缘发育向外翻的孔缘; 这些外翻 的孔缘将相邻壳壁连起. 内部结构不清楚.

比较: 在壳形和壳壁结构上,这类球形放射虫与新 种Paraantygopora porosa及Antygopora ordovicica Maletz and Bruton相似, 但这类球形放射虫壳壁更薄, 壳孔
更小、更密集，壳壁发育不完整，明显不同与后两种. 由于内部结构不清, 既无法对比已知属种, 也无法建立 新属种.

产地和层位: 罗家村剖面第2层和第3层, 九曲脑剖 面第2层、第3层和第 5 层，滚子圤剖面第 1 段和第 2 段 (图3).

科末定Family incertae

布朗球属(新属)Genus Bruanosphaera n. gen. Ma \& Feng

模式种 Bruanosphaera sinensis n. sp.

属名来源: 纪念德国放射虫古生物学家Andreas Braun首次在华南寒武系纽芬兰统地层中发现该属化 石. Sphaera(球形的), 反映形态特征.

鉴定要点: 新属壳体球形或近球形, 无外刺, 由3层 同心壳组成; 外壳厚, 格子状壳, 其孔呈规则的六边形; 第 2 层壳直径约为外壳直径的 $1 / 3$, 第 3 层壳直径约为第 2 层壳直径的 $1 / 3$; 各壳体之间由细弱的放射棒相连. 中 心囊无初始骨针.

比较: 新属外壳以规则的格子状壳体结构为特征, 明显不同于早古生代放射虫已知属种，与晚古生代及 中-新生代一些放射虫属相类似, 例如Trilonche、Archaeocenosphaera等，但以缺少放射刺、具有3层壳明 显区别于这些放射虫属, 故命名为新属.

时代分布: 寒武纪纽芬兰世和第二世; 华南.

中华布朗球虫(新种)Bruanosphaera sinensis n. sp. Ma \& Feng

图6h 6m

Spherical radiolarian Braun, Chen, Waloszek, and Maas, 2007, p. 146, fig. 4, a-d.

Spherical radiolarian Cao, Feng, Feng, and Ling, 2014, p.5, fig. 4, L-N.

Spherical radiolarian Chang, Feng, and Zhang, 2018, p.915, fig. 3, 4-7.

材料: 罗家村剖面第2层灰岩结核中产出7枚化石, 第3层泥灰岩中产出9枚化石, 第5层钙质泥岩产出24枚 化石; 九曲脑剖面第2层灰岩结核中产出 12 枚化石, 第5 层灰岩中产出9枚化石; 滚子圤剖面第1段灰岩结核中 
产出10枚化石, 第2段泥灰岩中产出 15 枚化石.

种名来源: sinensis(Latin, adj.), 中国的.

描述: 壳体球形, 由3个同心格子壳组成, 同心壳之 间由细的放射樑相连(图6h2、6h3). 外壳直径为 $86 \sim 233 \mu \mathrm{m}$ (平均值 $158 \mu \mathrm{m}$ ), 壳体表面均匀的布满六边 形格子状小孔(图6h1、6i1、6j1、6k1)，小孔直径为 $5.3 \sim 14.7 \mu \mathrm{m}$ (平均值 $10.9 \mu \mathrm{m}$ ), 无外刺. Micro-CT显示第 2 层壳直径约为外壳直径的 $1 / 3$, 第 3 层壳直径约为第 2 层壳直径的1/3. 中心囊无初始骨针(图6h2、6h3).

比较: 这类具六边形格子状外壳的球形放射虫最 早由Braun等(2007)发现于陕西宁强纽芬兰统(Terreneuvian)宽川铺组(p.146, fig.4, a-d)和浙江江山荷塘组 (p.145, fig.3)硅质岩地层中. 然而, 由于标本保存不完 整等问题，并未对该类型放射虫化石进行系统分类学 研究. 随后, Cao等(2014)在湖北剓归九曲脑剖面水井 沱组(Cambrian Series 2)下段灰岩结核(p.5, fig. 4, L-N) 和Chang 等(2018)在湖北剓归罗家村剖面岩家河组 (Terreneuvian)上段灰岩结核(p.915, fig. 3, 4-7)地层中, 均发现了这类球形放射虫化石. 此外, 自2011年以来, 笔者在研究区多个剖面(九曲脑剖面, 罗家村剖面和滚 子圤剖面)的水井沱组地层中也发现了该类型放射虫 化石，表明该类格子状球形放射虫在华南寒武系下部 地层中普遍存在.

由于多数标本内部重结晶较强, 一直没有获得其 内部结构资料. 从当前少数保存较好样品的 CT 照相来 看, 这类标本具 3 个同心格子壳, 并有细的放射棒相连, 缺少初始骨针, 结合外壳缺少放射刺, 当前新种很容易 与已知放射虫物种相区分.

正模：图6h，样品编号LJB-7; SEM照片编号4-1191.

产地和层位: 罗家村剖面第2层和第3层, 九曲脑剖 面第2层和第5层, 滚子地剖面第1段和第2段(图3).

\section{7 结论}

通过对鄂西剓归地区寒武系篫竹寺阶水井沱组放 射虫化石的特征描述和分类学研究, 得出以下结论:

(1) 鄂西剓归地区寒武系筇竹寺阶水井沱组放射 虫化石比较常见, 均为球形多囊虫类, 可以归属 4 种类 型：2个新属新种(Paraantygopora porosa和Braunosphaera sinensis), 1 个未定种(Tetrasphaera? sp.), 还有
1 个属种分类位置不确定的球形放射虫化石. 其中, Paraantygopora porosa、Braunosphaera sinensis和分 类位置不定的球形放射虫化石属于泡沫虫目, Tetrasphaera? sp.的科目位置未定.

（2）水井沱组放射虫动物群壳体结构复杂, 已经形 成发育的或不发育的同心层圈结构. 其中多数壳体的 壳层由绷带状板片融合形成的网状结构, 或称为穿孔 板状结构. 这些孔具有外翻形成的孔缘, 孔缘长短不 一，长者将不同壳体连接起来. 这些放射虫化石与奥 陶纪早期的一些放射虫属种壳体结构类似. 少数放射 虫化石具有网格状壳层, 这类化石在华南地区寒武纪 早期地层中有许多报道, 但它们与早古生代其他层位 放射虫化石壳体结构明显不同, 更类似晚古生代及中 生代一些放射虫化石的壳层结构.

(3) 到目前为止, 华南水井沱组放射虫动物群共由 6 个属级分类单元组成, 他们具有清晰的或发育不完整 的同心层, 壳体结构相当复杂, 这些特征表明寒武纪第 二世筇竹寺期放射虫已经爆发繁盛，这与浅水相区宏 体生物群的爆发繁盛可能为同步发生.

致谢本文放射虫化石扫描电子显微镜照相和能谱分析 在中国地质大学地质过程与矿产资源国家重点实验室完 成, Micro-CT照相在中国地质大学(武汉)生物地质与环境 地质国家重点实验室进行。感谢澳大利亚昆士兰大学Jonathan C. Aitchison教授和日本东北大学Noritoshi Suzuki 博士在放射虫分类学研究方面的有益探讨.

\section{参考文献}

陈平. 1984. 湖北宜昌计家坡下寒武统底部小壳化石的发现及其意 义. 地层古生物论文集, 2: 49-64, 164-165

冯增昭, 彭勇民, 金振奎, 鲍志东. 2002. 中国早寒武世岩相古地理. 古地理学报, 4: 1-12, 97-98

冯增昭, 彭勇民, 金振奎, 蒋盘良, 鲍志东, 罗璋, 鞠天吟, 田海芹, 汪 红. 2001. 中国南方寒武纪岩相古地理. 古地理学报, 3: 1-14

郭俊锋. 2009. 湖北宜昌早寒武世岩家河生物群研究. 博士学位论文. 西安: 西北大学. 1-166

黄慧琼, 许效松, 刘宝珺. 1988. 湘西-黔东早震旦世大塘坡组锰矿中 放射虫的发现及环境意义. 岩相古地理, 3-4: 51-61

林天瑞, 彭善池, 朱学剑. 2004. 峡东地区早寒武世水井沱组古盘虫 类三叶虫的再研究. 古生物学报, 43: 502-514

刘鹏举, 尹崇玉, 陈寿铭, 李猛, 高林志, 唐烽. 2012. 华南峡东地区埃 
迪卡拉(震旦)纪年代地层划分初探. 地质学报, 86: 849-866

牟传龙, 梁薇, 周恳恳, 葛祥英, 康建威, 陈小炜. 2012. 中上扬子地区

早寒武世(纽芬兰世-第二世)岩相古地理. 沉积与特提斯地质, 32:

$41-53$

潘时妹, 冯庆来, 常珊. 2018. 湖北宜昌寒武系纽芬兰统岩家河组小 壳化石. 微体古生物学报, 35: 30-40

钱逸, 陈孟莪, 陈忆元. 1979. 峡东地区下寒武统黄鳝洞组的古动物 化石. 古生物学报, 18: 207-232, 327-330

汪洋, 李勇, 张志飞. 2010. 峡东水井沱组顶部微体骨骼化石初探. 古 生物学报, 49: 511-523

王玉净, 成俊峰, 张元动. 2008. 新疆库鲁克塔格地区中奥陶统黑土 凹组的放射虫新属种. 古生物学报, 47: 393-404

杨爱华, 朱茂炎, 张俊明, 赵方臣, 吕苗. 2015. 扬子板块埃迪卡拉系 (震旦系)陡山沱组层序地层划分与对比. 古地理学报, 17: 1-20

张兴亮, 舒德干. 2014. 寒武纪大爆发的因果关系. 中国科学: 地球科 学 44: 1155-1170

张文堂, 李积金, 钱义元, 朱兆玲, 陈楚震, 张守信. 1957. 湖北峡东寒 武纪及奥陶纪地层. 科学通报, 2: 145-146

朱茂炎. 2010. 动物的起源和寒武纪大爆发: 来自中国的化石证据 古生物学报, 49: 269-287

朱茂炎, 杨爱华, 袁金良, 李国祥, 张俊明, 赵方臣, Ahn S Y, 苗兰云. 2019. 中国寒武纪综合地层和时间框架. 中国科学: 地球科学, 49: $26-65$

Afanasieva M S, Amon E O, Agarkov Yu V, Boltoskoy D S. 2005. Radiolarians in the fossil record. Paleontol J, 39(Suppl 3): 135-392

Aitchison J C, Flood P G, Malpas J. 1998. Lowermost Ordovician (basal Tremadoc) radiolarians from the Little Port Complex, western Newfoundland. Geol Mag, 135: 413-419

Aitchison J C, Suzuki N, Caridroit M, Danelian T, Noble P. 2017. Paleozoic radiolarian biostratigraphy. In: Danelian T, Caridroit M, Noble P, Aitchison J C, eds. Catalogue of Paleozoic radiolarian genera. Geodiversitas, 503-531

Braun A, Chen J, Waloszek D, Maas A. 2007. First Early Cambrian Radiolaria. Geol Soc Lond Spec Publ, 286: 143-149

Campbell A S. 1954. Radiolaria. In: Moore R C, ed. Treatise on Invertebrate Paleontology. Part D-Protista 3, Geology Society of America and University of Kansas Press. D11-D163

Cao W C, Feng Q L, Feng F B, Ling W L. 2014. Radiolarian Kalimnasphaera from the Cambrian Shuijingtuo Formation in South China. Mar Micropaleontol, 110: 3-7

Cawood P A, Wang Y J, Xu Y J, Zhao G C. 2013. Locating South China in Rodinia and Gondwana: A fragment of greater India lithosphere? Geology, 4: 903-906

Cayeux L. 1894. Les preuves de l'existence d'organismes dans le terrain précambrien. Première note sur les Radiolaires précambriens. Société Géologique de France, Bulletin. Séries 3: 197-228
Chang S, Feng Q, Zhang L. 2018. New siliceous microfossils from the Terreneuvian Yanjiahe Formation, South China: The possible earlist radiolarian fossil record. J Earth Sci, 29: 912-919

Conway M S, Chen M. 1990. Blastulospongia polytreta n. sp., an enigmatic organism from the Lower Cambrian of Hubei, China. J Paleontol, 64: 26-30

Dai T, Zhang X L, Peng S C. 2016. Morphology and development of the eodiscoid trilobite Tsunyidiscus yanjiazhaiensis from the Cambrian (Stage 3, Series 2) of South China. J Systatic Palaeontol, 14: $75-89$

Danelian T, Bengtson S. 2009. The evolutionary significance of a Lower Cambrian spicular entactinarian form from South Australia. Interrad 12, Abstracts. 53-54

Danelian T, Moreira D. 2004. Palaeontological and molecular arguments for the origin of silica-secreting marine organisms. Comptes Rendus Palevol, 3: 229-236

David T W, Howchin W. 1896. Note on the occurrence of casts of Radiolaria in Pre-Cambrian (?) rocks, South Australia. Proc Linnean Soc New South Wales, XXI: 571-583

Decelle J, Suzuki N, Mahé F, de Vargas C, Not F. 2012. Molecular phylogeny and morphological evolution of the acantharia (Radiolaria). Protist, 163: 435-450

Deflandre G. 1949. Les soi-disant radiolaires du Précambrien de Bretagne et la question de l'existence de radiolaires embryonnaires fossils. Bulletin de la Société Zoologique de France, 74: 351-352

De Wever P, Dumitrica P, Caulet J P, Nigrini C, Caridroit M. 2001. Radiolarians in the sedimentary record. Amsterdam: Gordon and Breach Science Publishers. 1-533

Dong X P, Andrew H K, Jere H L. 1997. Late Cambrian Radiolaria from Hunan, China. J Paleontol, 71: 753-758

Dumitrica P, Caridroit M, De W P. 2000. Archaeospicularia, ordre nouveau de radiolaires: Une nouvelle étape pour la classification des radiolaires du Paléozoïque inférieur. C R Acad Sci, 330: 563-566

Ehrenberg C G. 1838. Über die Bildung der Kreidefelsen und des Kreidemergels durch unsichtbare Organismen. Abhandlungen der Koniglischen Akademie der Wissenschaften, zu Berlin. Jahrgang: 59-147

Ehrenberg C G. 1875. Fortestzung der mikrogeologischen Studien als Gesammtuebersichtder mikroskopischen Palaeontologie gleichartig analysirterGebirgsarten der Erde, mit specieller Rucksicht auf den Polycystinen-Mergel von Barbados. Abhandlungen der Koeniglische Akademie der Wissenschaften, zu Berlin. Jahrgang: 1-226

Guo J F, Li Y, Li G X. 2014. Small shelly fossils from the early Cambrian Yanjiahe Formation, Yichang, Hubei, China. Gondwana Res, 25: 999-1007

Ishitani Y, Ishikawa S A, Inagaki Y, Tsuchiya M, Takahashi K, 
Takishita K. 2011. Multigene phylogenetic analyses including diverse radiolarian species support the "Retaria" hypothesis-The sister relationship of Radiolaria and Foraminifera. Mar Micropaleontol, 81: 32-42

Li Z X, Bogdanova S V, Collins A S, Davidson A, De Waele B, Ernst R E, Fitzsimons I C W, Fuck R A, Gladkochub D P, Jacobs J, Karlstrom K E, Lu S, Natapov L M, Pease V, Pisarevsky S A, Thrane K, Vernikovsky V. 2008. Assembly, configuration, and break-up history of Rodinia: A synthesis. Precambrian Res, 160: $179-210$

Maletz J. 2011. Radiolarian skeletal structures and biostratigraphy in the early Palaeozoic (Cambrian-Ordovician). Palaeoworld, 20: 116133

Maletz J, Bruton D L. 2005. The Beothuka terranova (Radiolaria) assemblage and its importance for the understanding of early Ordovician radiolarian evolution. Geol Mag, 142: 711-721

Maletz J, Bruton D L. 2007. Lower Ordovician (Chewtonian to Castlemainian) radiolarians of Spitsbergen. J Systatic Palaeontol, 5: 245-288

Müller J. 1858. Uber die Thalassicollen, Polycystinen und Acanthometrendes Mittelmeeres. Konigliche Preussische Akademie der Wissenschaftenzu Berlin, Abhandlungen, Jahre. 1-62

Nazarov B B. 1973. Radiolarians from the Lowermost Horizons of the Batenev Mountain Ridge. In: Problems of Paleontology and Biostratigraphy of the Lower Cambrian of Siberia and the Far East. Nauka, Novosibirsk. 5-13

Nazarov B B. 1988. Paleozoic Radiolaria Practical Manual of Microfauna of the USSR. vol.2. Leningrad, Nedra. 1-232

Obut O T, Iwata K. 2000. Lower Cambrian Radiolaria from Gorny Altai (southern West Siberia). J Geol Geophys, 41 (Suppl. News of Paleontology and Stratigraphy Nos. 2-3): 33-37

Okada Y, Sawaki Y, Komiya T, Hirata T, Takahata N, Sano Y, Han J, Maruyama S. 2014. New chronological constraints for Cryogenian to Cambrian rocks in the Three Gorges, Weng'an and Chengjiang areas, South China. Gondwana Res, 25: 1027-1044

Peng S C. 2009. The newly-developed Cambrian biostratigraphic succession and chronostratigraphic scheme for South China. Chin Sci Bull, 54: 4161-4170

Riedel W R. 1967. Subclass Actinopoda. In: Harland W B, Holland C H, House M R, Hughes N F, Reynolds A B, Rudwick M J S, Satterthwaite G E, Tarlo L B H, Willey E C, eds. The Fossil Record. A Symposium with Documentation. London: Geological Society of London. 291-298

Shu D G, Isozaki Y, Zhang X L, Han J, Maruyama S. 2014. Birth and early evolution of metazoans. Gondwana Res, 25: 884-895

Simpson A G B, Roger A J, Silberman J D, Leipe D D, Edgcomb V P, Jermiin L S, Patterson D J, Sogin M L. 2002. Evolutionary history of "early-diverging" eukaryotes: The excavate taxon carpediemonas is a close relative of Giardia. Mol Biol Evol, 19: 1782-1791

Steiner M, Li G X, Qian Y, Zhu M Y, Erdtmann B D. 2007. Neoproterozoic to Early Cambrian small shelly fossil assemblages and a revised biostratigraphic correlation of the Yangtze Platform (China). Palaeogeogr Palaeoclimatol Palaeoecol, 254: 67-99

Wang Y J, Cheng J F, Zhang Y D. 2008. New radiolarian genera and species of Heituao Formation (Ordovician) in the Kuruktag region, Xinjiang. Acta Palaeontol Sin, 47: 393-404

White R D. 1986. Cambrian Radiolaria from Utah. J Paleontol, 60 : 778-780

Won M Z, Below R. 1999. Cambrian Radiolaria from the Georgina Basin, Queensland, Australia. Micropaleontology, 45: 325-363

Won M Z, Iams W J. 2002. Late Cambrian radiolarian faunas and biostratigraphy of the Cow Head Group, western Newfoundland. J Paleontol, 76: 1-33

Won M Z, Iams W J. 2011. Earliest Arenig Radiolarians from the Cow Head Group, western Newfoundland. J Paleontol, 85: 156-177

Zhang Z F, Zhang Z L, Li G X, Holmer L E. 2016. The Cambrian brachiopod fauna from the first-trilobite age Shuijingtuo Formation in the Three Gorges area of China. Palaeoworld, 25: 333-355

(责任编委: 朱茂炎) 